San Jose State University

From the SelectedWorks of Ted M. Coopman

May 24, 2009

\title{
Networks of Dissent: Emergent Forms in Media Based Collective Action
}

Ted M. Coopman, San Jose State University 
Networks of Dissent: Emergent Forms in Media Based Collective Action

\author{
Ted M. Coopman, Lecturer \\ Department of Television, Radio, Film, and Theatre \\ Department of Communication Studies \\ San José State University \\ Hugh Gillis Hall 101 \\ San José, CA 95192-0098 \\ tmcoopman@yahoo.com
}

206-214-8625

A paper submitted to the Mass Communication Division of the International Communication Association annual convention 2009 


\begin{abstract}
The micro radio movement expanded over the course of 1990s and resulted in the creation of a Low Power Radio Service in 2000. Micro radio activists successfully leveraged the then emerging Internet and other digital technologies to further their cause. By doing so, participants developed new modes of organization and repertoires of action unique to the new interface between analog and digital worlds. In exploring this phenomenon, I developed dissentworks theory - describing how collective action emerges within digital environments. I offer his approach as a tool to reassess the impacts of an infrastructural approach to media based dissent collective action.
\end{abstract}




\section{NETWORKS OF DISSENT: EMERGENT FORMS IN MEDIA BASED COLLECTIVE}

\section{ACTION}

This study investigates a developing mode of collective action under the impact of Information and Communication Technologies (ICTs). I identify this new mode which I term a "dissent network" and test my theoretical assumptions on its behavior through the examination of a case study of a media-based collective action project - The Micro Radio Movement (MRM). The MRM was an effort to pressure the Federal Communications Commission (FCC) to tolerate the creation of low power community radio stations outside normal licensing schemes through overwhelming the system with unlicensed stations in acts of electronic civil disobedience (Author, date, 2000a, b, c; Opel, 2004; Walker, 2001). I was particularly well placed to analyze the increased level of interaction and participation afforded by the use of now seemingly rudimentary applications such as email, indexing websites, and listservs. It appeared to me that the ongoing development of the Internet and ICTs in general played a critical role (Author, date).

My research and participation in the MRM during the expansion of the Internet in the 1990s led me to question the impacts of digital networks, as well as those of related technologies, on collective action. I observed how relatively homogeneous networks and nodes combined to form relational, action oriented, heterogeneous networks. These appeared to materialize via an unofficial consensus on the failure of existing institutions and regimes of control to address unmet community needs. While similar to traditional social networks, these networks were enabled and magnified by digital technology. This was not dissent merely grounded in protest, but the removal of consent to a system's dominance and legitimacy over a particular sphere - the mainstream media. It was the development of alternative systems to meet community needs. By 
demonstrating the viability of other approaches, these new systems challenged the validity, exclusivity, and "natural" purview of existing systems over their domain.

\section{Conceptualizing Collective Action in a Digital Environment}

The development of advanced communication technologies and networks, especially in the last 20 years, has revolutionized many aspects of life. Humans have a "communication imperative" (Thurlow and Brown, 2003; Thurlow, Lengel, and Tomic, 2004) that drives us to maximize our communication satisfaction and interaction. We circumvent any obstacles that interfere with our relational fulfillment. Researchers are beginning to address this trend and explore if technology is altering the fundamentals of collective action (Armond, 2001; Arquilla \& Ronfeldt, 2001; Bimber, Flanagin, \& Stohl, 2005; Author, date; Flanagin \& Stohl, 2005; Morris, 2004; Pike, 2005; Shumate \& Pike, 2006).

Collective action and social movements are an incredibly complex mix of social phenomena that do not lend themselves to comprehensive or definitive analysis. In order to try to understand how certain collective action projects develop under the influence of digital technologies I have synthesized some critical elements of existing theory and practice to create an approach that better interrogates new forms of collective action as they emerge; specifically, forms of collective actions with the intention or result of developing alternative structures to meet community needs.

Benda (1978/91), in his analysis of communist era Czechoslovakia proposed that rather than futile direct resistance or attempts to reform an overwhelmingly powerful inherently corrupt, and oppressive regime, a more productive strategy was to create a "Parallel Polis" - a second culture of social and cultural institutions that exist outside mainstream culture. 
Conceptually, these outside institutions are more in tune with actual human needs and lack the oppressive qualities of state or mainstream ones. I argue that analysis of the drive to create a micro radio system in the U.S. is well served by building on the idea of dissent through the removal of consent to an existing system (in this case mainstream media) through the construction of a parallel system.

Earlier views on social movement formation were grounded in deviancy. Disaffected populations acted out (Kornhauser, 1959) or social control mechanisms that traditionally constrained civil disruption failed (Gusfield, 1994; Useem, 1998). However, the more rationalist economic resource mobilization approach has dominated social movement theory (MacCarthy and Zald, 1973; Tilly, 1978). Within this sphere, Tilly's (1978) and McAdam's (1982) political resource mobilization broadened the conceptualization of resources. McAdam (1982) further elaborated on the mobilization process with his three-phase cognitive liberation approach. This involved identification of the problem, a solution, and the probability of its success. Rather than viewing these approaches in opposition, they may be viewed (broadly) as steps in the development of a process. Disaffection motivates people and social control mechanisms may break down over time, or rather, fail to develop or evolve to keep pace with broader sociocultural or technological developments. These opportunities may foster cognitive liberation as they are discovered. The goals of social movement organizations may also be emergent instead of dictated through a command structure and diffused throughout the movement. The marshalling of resources is certainly a key to success, but the desire and opportunity to act must exist at the onset.

Eyerman and Jamison's (1992) cognitive praxis approach broadens the conversation by combining the technology and organizational dimensions of collective action and adding the idea 
of a unifying cosmology to maintain and drive movements forward. Melucci's (1996) new social movements perspective grasps the increased complexity and changes in information-based economies. The resources of information systems are knowledge and culture. The construction of community and the creation of cultural codes are, in his analysis, more central than protest over who-gets-what. Conflicts that form the impetus for social movements involve the acquisition, creation, use, and distribution of internal resources, as opposed to more traditional labor or class issues that battled over the wider societal distribution of resources. Again, this is not a grand theory of social movements, as the battle over basic resources and wealth distribution goes on, but a particular aspect of collective action.

The social networks that undergird society combine with networked information and communication technologies to become something bigger, interdependent, and more complex (Wellman, 1988). Reflecting back on resource mobilization, the social movement organization becomes a networked organization - a collection of actors engaged in repeated and enduring exchange relationships with no central legitimate authority, its own distinct logic, and comparative efficiencies (Podolny and Page, 1998; Powell, 1990). Internal legitimacy, accomplished through relational density, becomes key to any external success (Provan, 2000). As Takahashi (2000) found, network members are bound together by a collective sense of fairness and a degree of altruism grounded in a perceived commonality. Within the context of much larger distributed network, formerly territorialized relationships grounded in physical space become a form of networked individualism and role-to-role relationships develop (Wellman, 2000). Collective action may occur where weak ties within a network develop into relationships of affinity, reciprocity, and mutual action. Reinforcement, a key to sustained participation, becomes easy to manage and is no longer tied to physical proximity. 
Information diffuses along established interaction pathways and overlapping interpersonal spheres link previously unconnected social sites. Knowledge is exchanged and successful repertoires emulated (Tarrow 1998, 2005).

Early network formation is based on learning and relationship building, which lays the groundwork for future mobilization (Podolny and Page, 1998; Provan, 2000). The more expansive the network, and the more the variability in the message or idea, increases the likelihood that it will transfer across cultural and social differences increases. While the core theme of a movement might be consistent, the potential options for action must be sufficiently diverse to allow people to comfortably participate (Mische, 2003). Since there is no center within these polycentric networks (Gerlach, 2001) to control and direct them, individuals and groups within the network may exert more influence. Successful tactical repertoires may spread and aggregate to take collective action in novel, self-organizing directions. This contradicts resource mobilization's contention that collective action is intentional (read directed) movement to achieve collective goods and any unintended benefits are beyond the scope of collective action or social movements. While this may be true of traditional organizational structures it does not extend to network organizations. So it is possible that that highly networked and distributed social movements are technically not movements at all and collective action starts to revert to earlier models of collective behavior and mass society. However, this does not necessarily move the effort to understand emerging phenomena forward.

Collective cover for one's actions lowers risk; increased non-compliance builds its own momentum (Scott, 1985, 1990) and cascades, much like the communication infrastructure, horizontally across traditional cultural, political, and social borders, and vertically in the multiple potential actions (Bleiker, 2000). Minimal separation between different social spheres (Watts, 
2003) and vast global networks permit large-scale, emergent and self-organized non-compliance with established political, cultural, social, and commercial regimes of control. In Bleiker's (2000) words, dissent becomes transversal. So at least in potential, the organizational structure, the ability to project power, normally reserved for coherent and intentionally directed social movements - is wedded to the unpredictability of the "mob" (Rheingold, 2002).

These trends in collective action theory, research, and practice, combined with the analysis of social networks under the impact of new media technologies and resistance sets the stage for the development of new models of action and interaction. I argue that a distinct mode of collective action has developed that is focused on aggregating participants into projects to develop parallel institutions to meet community needs. This is largely dependent on leveraging new communication technologies and networks to share resources and open doors to large-scale diverse participation. Therefore, I propose a new perspective on current and emerging novel forms of activism and cooperation.

\section{Dissentworks}

A dissent network is an action-oriented, relational, heterogeneous network comprised of homogeneous networks/nodes (individuals, groups, or organizations) emerging via an unofficial consensus on the failure of existing institutions (state or private) or regimes of control to meet community needs enabled and magnified by digital technology. The act of dissent in the dissent network is dissent through the removal of consent to the existing system - the creation/adoption of an alternative system through the abandonment of the existing regime. Participants no longer consent to the confines of the existing regime's control.

At its core, a dissent network is an infrastructural project. It is infrastructural in the sense that its purpose is to create new systems or institutions (Benda, 1978/91). A dissent network 
represents a different collective response than mobilizing against the government for redress; disrupting society or commerce to force compliance; or petition for reform by ruling elites. A dissent network focuses on the creation or utilization of new forms of action and organization to meet immediate community needs outside the bounds of existing regimes. These systems provide alternatives for participants and simultaneously challenge existing regimes merely by demonstrating "another world is possible" - it may be thought of as a proof of concept.

Dissentworks theory is founded on four testable theoretical assumptions: A consensus on systems failure; relational density; process and resource sharing; and the centrality of digital networks.

The core theoretical assumption in dissentworks is when a consensus emerges that a system fails to meet individual or collective needs individuals and groups will create or seek out systems that will. The decision to create or adopt a new system rather than attempt to reform an existing system is based on a combination of practical feasibility, the degree of antipathy towards the existing system, and the level of acceptable risk/cost. Digital networks lower costs through resource sharing, increase feasibility, and lower risk through distribution and collective cover.

The creation and development of dense relational networks allows autonomous nodes and networks to effectively cooperate to form effective and coherent heterogeneous networks while maintaining autonomy. Traditionally, social movements oscillate between latency and mobilization. For traditional social movement organizations, the greater a network's diversity and dispersion, the more difficult interaction and facilitating effective ties become (Shumate and Pike, 2006). ${ }^{1}$

However, I propose that a dissent network promotes relational density at the sub-network level through diverse communities of practice existing within a network. Members of 
homogeneous groups within the larger network act as brokering and bridging agents when cooperating via sub-networks or distributed working groups (Diani, 2003; Tarrow, 1998). This process fosters the heterogeneous network of homogeneous sub-networks. In the case of a dissent network, high internal relational density contributes to the network's robustness. The dissent network acts as the environment for the nodes and organizations within it.

Process and resource sharing is key to a successful dissentwork. The product or purpose of a system (mobilization) cannot be separated from the process of how the system is organized (latency). Social movements frame collective identity through action and interaction within the movement and how the movement views itself and, through its actions such as protests, how it defines itself.

A dissent network organically solves the latency mobilization issues in digital environments by collapsing or integrating latency's identity, participant socialization, and the development of best practices into mobilization's application of resources to effect social change (Shumate \& Pike, 2006). A dissent network is perpetual mobilization, involving the action of constructing and maintaining an alternative structure. During this process, the act of member participation facilitates building identity, socializes participants, and develops best practices through direct action, resource sharing /pooling and detail to organizational process.

The affordances of ICTs and digital networks facilitate the creation of functional parallel regimes and systems outside the bounds of existing dominant systems. The development of new media technologies and digital networks facilitates the projection of power and greatly reduces the need for a traditional organizational structure (Bimber, Flanagin, \& Stohl, 2005). Under the impact of new communication technologies, transaction costs and the impacts of free riders are significantly blunted (Flanagin \& Stohl, 2005). Therefore, participation and reinforcement of 
association becomes easier. Digital networks mitigate the pitfalls of central process and resource control, which can lead to cooptation, disruption, or leadership/resource decapitation. Moreover, these networks allow for greater flexibility and adaptability to local environments and can overcome coordination and organizational issues for widely distributed (national or global) groups.

Method

The idea of a dissent networks perspective emerged over nine years investigating and participating in the MRM. The patterns I detected emerged over multiple studies on various aspects of the MRM. Therefore, the history of the movement and my observations provide the basis of my analysis. My method is broken down into two primary areas: (1) historical analysis and (2) observation and field notes.

Historical Analysis

The historical analysis of the MRM is derived from two main areas, the existing literature and media accounts. The existing literature on the MRM is scant, but many of the sources contain rich data that add novel perspectives and often support my own observations and analysis. The MRM participants created another type of literature I relied on. Several participants have written books and articles about their experiences. I also analyzed media accounts and press stories to construct an historical context and capture the participants' perspectives and the chronologies of their activities. Like traditional social movement actors, MRM participants leveraged media coverage as part of their overall campaign. I also collected and archived print articles over the period from 1993-2002.

Observations and Field Notes 
From 1993 to 2002 I participated in the MRM and interacted with members both online and offline. I first encountered the movement as a researcher and later as both a researcher and participant. The Micro Radio Network (MRN) listserv was the MRM's main communication channel and has been in operation since 1998. At its peak, the listserv had approximately 200 members (Author, date). This listserv is public, although the archives were restricted after the National Association of Broadcasters used excerpts in their FCC comments. This data source is particularly rich because I collected the listserv messages in real time as a participant, which facilitates a deeper understanding of interaction in an online environment (Paccagnella, 1997). Data for this study were collected from 1998 to 2002. Personal communications consisted of email correspondence and face-to-face meetings with participants from 13 different micro radio stations in 9 states. I visited over 64 station websites representing 28 states from 1995 to 2002 and obtained print publications and propaganda people sent me and I collected at numerous benefits and gatherings. All data were computer indexed for ease of access.

\section{The Micro Radio Movement}

The MRM was an emergently-structured, loosely-bounded, and organizationally ad hoc network. This network spread organically over the course of the 1990s to encompass diverse participants held together by an informal identity. This identity developed from the general tropes of free speech, community empowerment at the local level, and resistance to media consolidation. The network had a thematic implicit identity as an alternative to existing media and a structure/scheme that partially or potentially facilitated its functioning as an alternative media system. The MRM developed around a combination of unlicensed broadcasting and logistical support for these operations combined with political agitation. The MRM was 
generally autonomistic, with no formal relationships or support from existing media reform organizations or political parties. ${ }^{2}$ There was a strong focus on infrastructure development to sustain the movement and create media outlets. This type of dissent network has distributed network structures that facilitate emergent process schemes. As there was no adhesion to central authority in a classic Leninist sense (Downing, 2002), inclusion was maintained through the informal development of process models that generally revolved around consensus decisionmaking. There was evidence of network (versus node to node) solidarity in the face of countermovement activity, as well as coordination and affinity. The key to development was commonlyaccessible systems that allow for sub-network formation and interactivity via mediated technologies and sporadic conferences as well as other face-to-face meetings.

\section{Consensus on System Failure}

When a consensus is reached that a particular regime or system no longer meets the perceived needs or requirements of a particular constituency, a dissent network may emerge. This emergence occurs when groups or individuals create structures or disseminate ideas that catch the attention of sympathetic constituencies. These constituencies must be receptive to both the perception of an unmet need as well as a potential alternative and are ready to adopt it and participate in its creation or maintenance.

The two characteristics of consensus forming around a dissent network consist of: (1) a clear delineation between it and an existing regime and (2) the network that emerges in response to its perceived failures and the determination for the development of this new system. This type of response is in contrast to a traditional social movement approach where members would seek reform of the existing system or other concessions or compliance from existing incumbent power structures. However, another strategy involves individuals and organizations constructing an 
alternative system to meet these unmet needs. The MRM began with two sets of unmet needs: the belief that radio provided an important and potentially economical tool for community outreach that existing media did not provide; and the belief that the existing media system was broken or corrupt.

Multiple actions, tactics, and statements, by participants, evidence the movement's consensus on systems failure. For example, Mbanna Kantako put WTRA in Springfield IL on the air for the residents of John Jay Homes public housing project to serve as an organizing tool to cope with police oppression, act as a channel that could overcome literacy issues and speak to the community's oral traditions, and counter local media coverage (Brinson, 2006; Fiske, 1996; Landay, 1998; Shields \& Ogles, 1992; Walker, 2001). While presaging the movement, Kantako's station exemplified the duel nature of the MRM. First, members were dissatisfied with the state of media in the U.S.: consolidation in commercial broadcasting, the increasing "professionalization" of public non-commercial broadcasting, market pressures, new federal regulations, and funding schemes all resulted in much of the public being removed from public radio (Howley, 2004). Moreover, activists involved with groups such as Food Not Bombs (feeding the poor and homeless) and EarthFirst! (direct action environmentalism) began exploring the possibilities of using radio as a community organizing tool (Edmondson, 2000; Tashtego, 1998).

Another example is Stephen Dunifer and his high profile federal court battle with the FCC. This was considered the flash point for the emergence of micro radio as a broader movement. His disgust at the media spectacle of the first Gulf War in 1990 the led him to found Free Radio Berkeley (FRB). As he put it, the U.S. media had "moved into a spare office at the 
Pentagon" (Author, date). It was Dunifer's perception that both commercial and public media had been co-opted by the Pentagon and became a propaganda tool for American foreign policy. In 1993, Dunifer, with the help of other activists, put Free Radio Berkeley on the air as an act of electronic civil disobedience (Author, date; Walker, 2001). Dunifer's connections with the activist community in the San Francisco Bay Area sparked interest in radio and led to the establishment of multiple stations, including San Francisco Liberation Radio (SFLR) and Free Radio Santa Cruz (FRSC).

The relatively small size of the FCC and widely inconsistent enforcement of broadcast regulations on unlicensed stations provided the rationale for the MRM activists' strategy (Author, date). This wholesale rejection of the existing media system as dysfunctional, the regulatory system as illegitimate, and the potential for the construction of a parallel autonomous system formed the foundation for the initial conceptualization of a dissent network.

\section{Relational Density}

Network coherency is the primary factor in assessing relational density. Moreover, relational density assesses whether dense, complex, and interlocking relationships develop between participants. The development of relational networks is also a characteristic of traditional social movements (McAdam, 1982). In a dissent network, relational density refers to smaller homogeneous networks linking into larger more heterogeneous networks. In the case of micro radio, the development of relational density began with pre-existing activist social networks. Stations emerged from groups in New York City (Steal this Radio), Philadelphia (Radio Mutiny), Boston (Free Radio Alston), and Austin (Free Radio Austin), as well individual political agitators in Cleveland (GRID Radio), San Marcos, TX (uKind), and Florida (Loni Kobres and Doug Brewer's "Party Pirate”), among others. Transient activists, students, and 
squatters, and eventually the establishment of websites and listservs brought these different subnetworks together.

In the San Francisco Bay Area, like other regions, activist communities often overlapped. Early micro radio activists exchanged program tapes, equipment, and expertise. Eventually digital networks facilitated membership in multiple communities of practice. These digital networks also allowed participants to act as informational and relational brokers to form bridges between groups that might not ordinarily align (Diani, 2003; Tarrow, 1998).

Relational density facilitates a robust network structure comprised of official and ad hoc communication channels. For example, early attempts at using listservs depended on using those developed by existing organizations such as RockRap Confidential and Industrial Workers of the World (IWW). Lyn Gerry and Sean Ewald developed Radio4all - initially for the conflicts surrounding the Pacifica Radio Network, but later more focused on the MRM - a largely hypertext indexing website in 1996 as well as the Micro Radio Network (MRN) listserv in 1998. The participation of activists from across the country introduced new perspectives to the movement. Overall, the network's distributed structure as it developed made it proactive and dynamic, thus able to respond and cooperate in novel ways. This cooperation was evidenced by solidarity, operational techniques and technical assistance, sharing of program content, and sometimes supplying replacement gear after an FCC raid.

Some MRM participants also acted as important brokers to existing organizations. Jesse Walker, an editor at the Libertarian Reason magazine, was a regular listserv participant and agitator often in conflict with Dunifer and other MRM regulars for his left libertarian and freemarket ideology. Moreover, his connection with the Cato Institute and other libertarian think tanks provided exposure for the movement and its goals. Despite overlaps in their views of 
authority and the role of government, Walker's libertarian ideology often clashed with movement anarchists' ideology on issues of commercial vs. non-commercial radio, religious radio, corporate rights and responsibilities, the role of more entrepreneurial micro broadcasters, and content restrictions. Combining this openness with the asynchronous nature of online deliberation and discussion fosters heterogeneity in the network (Postmes, Spears, and Lea, 2000; Rafaeli and Sudweeks, 1997).

The MRM's loose boundaries and openness facilitated the dilution of the more radical founders' positions and tactics, thus moderating methods and goals. Unlike traditional Leninist movements, movement intellectuals and founders were unable to discipline other movement members. Thus, the large numbers of new entrants and those activated by the movement but not directly connected to its founders or history were able to shift the focus from a rebellion to a reform agenda. While a loosely organized and emergent dissent network is prone to cooptation by more traditional social movement processes, the early establishment of dense rational networks can carry over and enhance the organizational ability of more traditional collective action.

While relational networks form the core of social movements, the reach and ease of use afforded by access to Information and Communication Technologies (ICTs) facilitates a diversity of participation that is simultaneously a strength and weakness in the development of alternative structures. However, relational density enhanced by ICTs can withstand the collapse of the larger dissent network by transitioning into pre-existing networks or evolving into new subnetworks.

Process and Resource Sharing 
Despite its distributed nature, a dissent network functions through its ability to collapse mobilization and latency into one process. That is, the building of the movement and the mobilization of the movement to take action largely meld into one process. The act of member participation facilitates identity building, socializes participants, and develops best practices through direct action, resource sharing, and detail to organizational process. A dissent network involves perpetual mobilization in which participants construct and maintain an alternative structure. For the MRM, the ability of many stations to get on the air stemmed directly from MRM members providing technical and tactical support.

At its core, the early MRM was a resource sharing collectivist endeavor. Pioneers such as Dunifer and Brewer also made transmitter kits, sold related equipment, and conducted workshops on transmitter construction. Much of the movement's energy focused on the rigors of getting a station on the air and keeping it there. The primary foe usually was not the FCC but equipment failure, technical difficulties, lack of funds, and locating technicians willing to participate. For example, the high cost of housing in Santa Cruz, CA, forced FRSC to relocate numerous times, at one point broadcasting from a bicycle cart. Activists used to shoe-string budgets were adept at raising funds and local bands were usually more than happy to support micro radio stations that were often the only outlets for their music. The ethics and methods of fundraising were also debated, such as DJ dues (derisively called "fee radio" by Free Radio Austin members) or underwriting and sponsorships. The strict anti-capitalist stance versus supporting local progressive businesses and the need for cash were regularly discussed on MRN. Getting ideas for different fundraising techniques and securing equipment donations was a prime resource benefit of the network. 
Exchanging organizational philosophies and techniques, such as how to make decisions or structure a station, was a common the theme on the MRN listserv and for workshops at MRM meet-ups and conferences. As in many activist groups in the 1990s, the MRM was highly interested in process issues. The importance of a functional structure that still reflected the station members' philosophies and ideologies was clear to most participants, as were the consequences for failure. For example, Free Radio Gainesville (FL) contacted the MRN listserv for input on its own structure as well as a workshop the station was facilitating at the upcoming April 1998 East Coast Micropower Radio Conference in Philadelphia. While listserv members agreed that consensus decision making was ideal, participants viewed this as a goal not easily attained. Conflicts often caused factionalism that led some collectives to collapse and others to splinter. An example of this occurred in Houston when Radio Montrose failed and a faction reformed as First Amendment Radio.

A dissent network's organizational structure tends to replicate itself on the local, intermediate, and network wide levels. In the MRM's case, many of the organizational and management issues that arose at the station level also confronted the movement as a whole. In a dissent network, governance falls to those willing and able to do the work at a given moment, typically a cadre of dedicated activists. With a highly distributed movement such as dissent network, consensus and process are almost a fetish (Epstein, 2001) producing a natural tendency for "wholearchies" composed of more traditional leaders or movement intellectuals that emerge (Eyerman \& Jamison, 1992; Op el, 2004). While the dynamism of highly flexible systems can create advantages over more traditionally organized and better-resourced opponents, the networks' dynamic nature can cause internal problems that undercut their overall effectiveness. 
The MRM's transition from a dissent network focused on expanding the number of stations and supporting existing outlets to a more traditional effort of reforming existing media regulation and law brought with it a need for legal experts rather than technical ones. In the movement's early stages, the Do-it-yourself (DIY) nuts and bolts operation of stations and production of content formed the latency/mobilization bridge. The need to interface with the FCC bureaucracy, navigate regulations, media law, and the legislative process required different techniques, knowledge, and skills that most movement participants did not possess. Having the necessary knowledge base has been part of the traditional barrier to citizen participation in the media regulation process. Therefore, the MRM's center of control shifted to those with experience as well as investment in the existing regime. Distributed participation and involvement were curtailed, breaking the latency/mobilization link and fostered the collapse of the dissent network and its capture by reformist elements.

The continuous integration of mobilization and latency fosters the development and maintenance of the MRM dissent network. However, this level of integration and action would not have been possible with the introduction of accessible digital networks.

\section{Centrality of Digital Networks}

At the core of the dissent networks typology is the creation of social bonds via the centrality of digital networks. The development of new media technologies and digital networks facilitates the ability to project power over wider areas, greatly reducing the need for a traditional organizational structure and physical infrastructure, and lowering transaction costs (Bimber, Flanagin, \& Stohl, 2005; Flanagin \& Stohl, 2005). Moreover, the ease of access to these networks greatly reduces the need for physical co-location to reinforce interest and participation 
(Tarrow, 1989). Through email, listservs, and web access individuals and groups have the ability to discover, participate, and add resources to the network. Every new member is a node that connects the network with that node's pre-existing associates. MRM participants could coordinate individually or with groups as needed based on mutually advantageous agendas and resources. General solidarity can be maintained with direct involvement or validation by other nodes in the network. The removal of one node, such as an organization, station, or individual, could not collapse the network. Finally, these networks allow for greater flexibility and adaptability to local environments and can overcome coordination and organizational issues for widely distributed national or global groups.

Early use of ICTs by micro radio activists roughly followed early adopters in the creation of web browsers and use of email in the early to mid 1990s. Pre-existing networks and online resources hosted initial organizing efforts. Meet-ups such as the first micro radio conferences in Oakland and San José CA in 1996 provided opportunities for participants to gather email addresses for mass mailing lists. One example of early adoption of online technology was the Association of Micro Power Broadcasters (AMPB) newsletter developed by Paul Griffin of Free Radio Berkeley beginning in 1994. The AMPB newsletter transitioned from paper to mass emailing and finally to regular listserv postings (Author, date).

Beginning in 1997, MRM-related websites and listservs created a progressively more robust network that supported and expanded the movement as the conflict between the MRM and the FCC (with support from the NAB) escalated in 1998-99. Increased FCC raids and seizures forced many stations to lower their local operational profiles, but the electronic network connecting participants maintained solidarity and mutual aid. 
The Micro Radio Network listserv (MRN) came online in January 1998 as the FCC moved aggressively to shut down stations and re-establish control in the wake of legal setbacks in the Dunifer case (Author, date). As listserv co-founder Lyn Gerry stated in her first post to the listserv, "The list, it is hoped, will be a tool in assisting with organizing politically, legally and technically for our mutual defense against the current stepped up campaign of attacks by corporate media and their government allies" (Author, date). MRN was a project of the Radio4all website. Radio4all had already become a popular index and information site and MRN caught on immediately. Reflecting on that time, Lyn Gerry said, "I perceived that there was a need for a nexus of information, and expanded the site accordingly" (Author, date) The combination of the website and the new listserv increased traffic at the Radio4all site, which averaged 400 hits per day as of January 1998 (a total of approximately 1/2 million hits). According to listserv operators, MRN had 119 subscribers as of August 1998. On average the listserv added 1 or 2 subscribers every week ${ }^{3}$ and reached 200 subscribers in 2000. Knowledge of the listserv spread beyond the initial membership through personal relationships forged in other campaigns. There were so many requests for legal advice from both lawyers and stations that a separate secure forum, MRN Legal, was created.

By 1999 the movement had extended into community groups and churches that petitioned local city councils for proclamations of support and generated negative local press when federal marshals silenced stations. The FCC, searching for a way to avoid the escalating public conflict, began to move on the petitions to create a Low Power Radio Service. The development of digital infrastructure during the 1990s was a key element in the success of the MRM and later in the creation of a LPFM service. The complex networks of websites, listservs, and personal 
contacts via email provided the structure that facilitated the formation of the MRM dissent network.

\section{Discussion}

The MRM brought together a wide variety of participants who shared the perception that the existing media system was not meeting their own needs, the needs of their communities, and the media's obligations to the general maintenance of democracy. The parallel development and popularization of the Internet provided the foundation for geographically dispersed groups and individuals to discover the MRM and participate. Moreover, the organizational advantages of comparatively fast and inexpensive communication allowed the movement to maximize scarce resources and coordinate on efforts in their struggle against the FCC and incumbent broadcasters. Radical activist technicians with both an interest in computers and radio helped propel free radio and the MRM into the Information Age (Author,date; Edmonson, 2000). Anarchist organizational strategies, inexpensive computing power, fast communication via email and listservs, indexing websites, and audio compression that facilitated the sharing of content proved to be highly effective in promoting the movement. The efficiencies and economies of scale that fueled the dot com boom also enabled a small number of media activists with scant resources to launch and maintain a national movement that eventually altered America's communication policy (Author, date).

My study of and participation in the MRM illustrated to me the value and impact of digital networks and new communication technologies in aiding collective action against resource-rich opponents. At its core, the formulation of dissentworks theory resides in four fundamental practical impacts. First, digital communication networks and advances in computing 
greatly reduce costs to participants and increase their ability to meaningfully engage in collective action. Second, these networks allow participants to share resources, especially intellectual resources such as expertise, in a highly efficient manner, thus lowering the cost of collective action irrespective of physical distance or distribution. Third, the Internet's organizational infrastructure provides the basis for organizing a dissent network, reducing the need to develop an entirely new structure or to rely on outside institutions, which may have their own agendas, to provide it. Finally, these three factors interact to create opportunities for developing semiautonomous structures that meet participants' needs and goals without depending on government or other institutions to actuate the group's demands.

The MRM reveals dissentworks theory's constituent elements. The movement began with a consensus among elements of the population that the current system was failing to meet community needs. The movement's formation centered on articulating the unmet need and creating a viable plan to address it. Over time, dense relational networks within and among preexisting groups emerged, creating a heterogeneous network of homogeneous sub-networks and nodes. The construction of movement identity (latency) and marshalling resources to take action (mobilization), become the same overall process. The act of member participation facilitates identity building, socializes participants, and fosters the development of best practices through direct action, resource sharing, and detail to organizational process. Finally, the digital networks prove central in building effective bonds necessary for the articulating a consensus on the system's failure, cultivating relational density through ease of interaction, and enmeshing latency and mobilization into one process. Dissent networks represent a shift into a new mode of collective action under the impact of pervasive digital communication networks. 
Finally, dissentworks provides new theoretical approach to explore collective action under the impact of ICTs bridging between traditional social movement theories and network approaches to provide an exploratory framework for emergent forms of media organization and action. 


\section{References}

Armond, P. (2001). Netwar in the emerald city: WTO protest strategy and tactics. In J. Arquilla, and D. Ronfeldt (Eds.), Networks and netwars (pp. 201-238). Santa Monica, CA: Rand.

Arquilla, J., \& Ronfeldt, D. (2001). The advent of netwar. In J. Arquilla, and Ronfeldt, D. (Ed.), Networks and netwar (pp. 1-28). Santa Monica: RAND.

Benda, V. (1978/91). The parallel polis. In H. G. Skilling \& P. Wilson (eds.) Civic freedom in eastern europe. St. Martin's Press, New York, pp 35-41.

Bilotta-Daily, Dharma \& Siska, Tracy J. (1999, January/February). F.C.C.'s interference argument grounded: Commercial radio, not micropower, in more frequent hazard for aviation. Fairness and Accuracy in Reporting, p. 3-4.

Bimber, B., Flanagin, A. J., \& Stohl, C. (2005). Reconceptualizing collective action in the contemporary media environment. Communication Theory, 15, 365-388.

Bleiker, R. (2000). Popular dissent, human agency, and global politics. Cambridge: Cambridge University Press.

Brinson, P. (2006). Liberation frequency: The free radio movement and alternative strategies of media relations. The Sociological Quarterly 47. 543-568

Author, (date)

Author, (date)

Author, (date)

Author, (date)

Author, (date)

Diani, M. (2003). "Leaders” or brokers? Positions and influence in social movement networks. 
In Diani, M. \& D. McAdam (Eds.), Social movements and networks: Relational approaches to collective action (pp. 105-122). New York: Oxford University Press.

Downing, J.H. (2002). The Independent media center movement and the anarchist socialist tradition. In N. Couldry \& J. Curran (Eds.), Contesting media power: Alternative media in a networked world (pp. 243- 258). New York: Rowan and Littlefield.

Edmonson, R. (2000). Rising up: Class warfare inn America from the streets to the airwaves. San Francisco: Librad Press.

Epstein, B. (2001). Anarchism and the anti-globalization movement. Monthly Review, 53(4). Retrieved [insert date here] from http://www.monthlyreview.org/0901epstein.htm Eyerman, R., \& Jamison, A. (1991). Social movements: A cognitive praxis. University Park, PA: Penn State Press.

Fiske, J. (1996). Media matters: Race and gender in U.S. politics. Minneapolis: University of Minnesota Press.

Flanagin, A. J., Stohl, C., \& Bimber, B. (2006). Modeling the structure of collective action. Communication Monographs, 73, 29-54.

Gerlach, L. P. (2001). The structure of social movements: Environmental activism and its opponents. In J. Arquilla \& D. Ronfeldt (Eds.), Networks and netwars: The future of terror, crime, and militancy (pp. 289-310). Santa Monica, CA: Rand.

Gusfield, J. R. (1994).The reflexivity of Social Movements: Collective behavior and mass society revisited. In E. Larana, H. Johnston, and J.R. Gusfield (Eds.) New Social Movements from Ideology to Identity. Philadelphia: Temple University Press (58-78)

Howley, K. (2004). Remaking Public Service Broadcasting: Lessons from Allston-Brighton Free Radio Social Movement Studies, (3). 221-240 
Human S. E. and Provan K. G. (2000). Building in the evolution of small-firm multilateral networks: A comparative study of success and demise. Administrative Science Quarterly, 45. 327-365.

Kornhauser, W. (1959). The politics of mass society. New York: Free Press

Landay, J. (1998). We are part of a restoration process of our people: An interview with Mbanna Kantako (Human Rights Radio). In S. Dunifer and R. Sakolsky's Freeing the Airwaves: A Free Radio Handbook. San Francisco: AK Press. pp.94-100.

MacCarthy, A., \& Zald, M. (1973). The trend of social movements in America. Morristown, NJ: General Learning Press.

McAdam, D. (1982). Political process and the development of black insurgency, 1930-1970. Chicago: University of Chicago Press.

Melucci, A. (1996). Challenging codes: Collective action in the information age. Cambridge, UK: Cambridge University Press.

Mische, A. (2003). Cross-talk in movements: Reconceiving the culture-network link. In M. Diani \& D. McAdam (Eds.), Social movements and networks: Relational approaches to collective action (pp. 258-280). New York: Oxford University Press.

Opel, A. (2004). Micro radio and the FCC: Media activism and the struggle over broadcast policy. Westport, CN: Praeger.

Paccagnella, L. (1997). Getting the seats of your pants dirty: Strategies for ethnographic research on virtual communities. Journal of Computer-Mediated Communication, 3(1). Retrieved March 3, 2003, from http://www.ascusc.org/jcmc/vol3/issue1/paccagnella.html

Podolny J. M. and Page K. L. (1998). Network forms of organization Annual Review of Sociology, 24. 57-76. 
Postmes, T., Spears, R., \& Lea, M. (2000). The formation of group norms in computer-mediated communication. Human Communication Research, 26, 341-371.

Rafaeli, S., \& Sudweeks, F. (1997). Networked interactivity. Journal of Computer-Mediated Communication, 2(4). Retrieved March 3, 2003 from http://www.ascusc.org/jcmc/vol2/issue4/rafaeli.sudweeks.html

Rheingold, H. (2002). Smart mobs: The next social revolution. Cambridge, MA: Perseus Publishing

Scott, J. C. (1985). Weapons of the Weak. New Haven, CN: Yale University Press.

Scott, J.C. (1990). Domination and the Arts of Resistance. New Haven, CN: Yale University Press.

Shields, S. O., \& Ogles, R. M. (1992, March). Black liberation radio: A case study of the micro-radio movement. Paper presented at 22nd annual meeting of the Popular Culture Association, Louisville, KY.

Takahashi, N. (2000). The emergence of generalized exchange. American Journal of Sociology, $105(4), 1105-34$.

Tashtego, D.J. (1998). Community struggle and the sweet mystery of radio. In S. Dunifer and R. Sakolsky's Freeing the Airwaves: A Free Radio Handbook. San Francisco: AK Press. pp.133-142.

Tarrow, S. (1998). Power in movement (2 $2^{\text {nd }}$ ed.). Cambridge, MA: Cambridge University Press. Tarrow, S. (2005). The new transnational activism. Cambridge, MA: Cambridge University Press. 
Thurlow, C. and Brown, A. (2003). Generation txt? The discourses of young people textmessaging. Discourse Analysis Online. Retrieved on December 13, 2006 from http://extra.shu.ac.uk/daol/articles/v1/n1/a3/thurlow2002003-01.html

Thurlow, C., Lengel, L. \& Tomic, A. (2004). Computer mediated communication: Social interaction and the Internet. London: Sage.

Tilly, C. (1978). From mobilization to revolution. Reading, MA: Addison-Welsey.

Tilly, C. (1986). European violence and collective action since 1700. Social Research 53: 159-84.

Useem, B. (1998). Breakdown theories of collective action. Annual Review of Sociology. 24. $215-238$.

Walker, J. (2001). Rebels on the air: Alternative history of radio in America, New York University Press, New York.

Watts, D. J. (2003). Six degree: The science of a connected age. New York: W.W. Norton \& Company Inc.

Wellman, B. (1988). Structural analysis: From method and metaphor to theory and substance. In B. Wellman \& S.Berkowitz (Eds.), Social structures: A network approach (pp. 19-61). Cambridge, England: Cambridge University Press.

Wellman, B. (2000). Changing connectivity: A future history of Y2.03K. Sociological Research Online, 4. Retrieved on June 1, 2003 from http://www.socresonline.org.uk/4/4/wellman.html 
${ }^{1}$ This is due to the focus of traditional movements on protest actions, which generally follow cycles of latency development followed by mobilization.

${ }^{2}$ Once the LPFM rule making went into affect the MRM became affiliated with some existing media reform organizations.

${ }^{3}$ Subscribers do not accurately reflect the number of participants. At this stage of the development of the Internet access was more limited and often (usually poor) activists shared accounts. For example, all members of the Free Radio Cascadia (OR) collective used the same account and name (thuja) when posting. 